\title{
Magnesium status in a population of type 2 diabetes mellitus in Morocco
}

\begin{abstract}
Background: Type 2 diabetes mellitus (T2DM) contributes to $90 \%$ cases of diabetes-the ninth leading cause of death. Magnesium (Mg) levels have been found consistently low in the patients with T2DM around the world.

Objective: The objective of our work was to assess the $\mathrm{Mg}$ status in the patients with T2DM.

Material and methods: A descriptive prospective study including 103 patients with type 2 diabetes mellitus (T2DM) was carried out at Avicenna Military Hospital in Marrakesh over a period of four months (October 2019 - January 2020). The patients with T2DM and age above 35 years with no history of $\mathrm{Mg}$ supplementation, cancer or autoimmune disease were included in the study. Blood samples were analyzed for fasting glucose, lipid profile, $\mathrm{HbAlc}$, and serum magnesium. The data were analyzed by SPSS version 16, Pearson correlation was performed to establish the relationship between $\mathrm{Mg}$ and metabolic variables in T2DM patients.

Results: The study included 103 T2DM patients with 56 (54.4\%) males and $47(45.6 \%)$ females. Prevalence of hypomagnesemia was $14.56 \%$. Mean age of the patients and duration of diabetes were $59 \pm 9$ years and $9 \pm 4$ years, respectively. Most common antecedent conditions were dyslipidemia (43.7\%), hypertension (42.7\%), and retinopathy $(25.2 \%)$. Hypomagnesemia was significantly associated with $\mathrm{HbAlc}(\mathrm{P}=0.003)$ and arterial hypertension $(\mathrm{P}=0.002)$. Magnesium had negative linear relationship with increased fasting blood sugar and $\mathrm{HbAlc}$
\end{abstract}

Conclusion: In Morocco, the prevalence of hypomagnesemia in T2DM patient is low, but it has negative linear relationship with fasting blood sugar and HbAlc.

Keywords: hypomagnesemia, type 2 of diabetes mellitus, Morocco, insulin resistance
Volume 9 Issue I - 202|

\author{
W Quiddi,' M Tarmidi,' A Mansouri, 3 ,4 M \\ Amine, ${ }^{3,4}$ H Baizri, ${ }^{2}$ A Boukhira,' S Chellak' \\ 'Clinical Biochemistry and Toxicology Department, Avicenne \\ Military Hospital- FMPM-Cadi Ayyad University- Marrakesh, \\ Morocco \\ ${ }^{2}$ Endocrinology Department, Avicenne Military Hospital-FMPM- \\ Cadi Ayyad University-Marrakesh, Morocco \\ ${ }^{3}$ Clinical Research Department, Mohammed VI University \\ Hospital, Morocco \\ ${ }^{4}$ Community Medicine and Public Health Department, \\ Bioscience et Health Research Lab, School of Medicine, Cadi \\ Ayyad University, Morocco
}

Correspondence: Dr.Wafa Quiddi, Clinical Biochemistry and Toxicology Department, Avicenne Military HospitalFMPM- Cadi Ayyad University- Marrakesh, Morocco, Tel +212687946777, Email wafaquiddi@gmail.com

Received: March 29, 202 | | Published: April |2, 202 |

\section{Introduction}

Diabetes is a serious and rising global issue, ranking it as the ninth leading cause of death around the globe. ${ }^{1}$ Type 2 diabetes mellitus (T2DM) is a multi-factorial, chronic, metabolic disorder characterized by persistent hyperglycemia. ${ }^{2}$ Approximately, 462 million people are suffering from T2DM all over the word, imposing a significant impact on human life and healthcare facilities. ${ }^{3}$ Globally, T2DM contributes to $90 \%$ of all diabetes cases. ${ }^{1}$ In the year 2016, the World Health Organization (WHO) reported total population of Morocco as 34378000 with overall prevalence of diabetes mellitus as $12.4 \%$ and 24,020 deaths attributable to diabetes. ${ }^{4}$ Therefore, diabetes accounts for major mortality and morbidity in Morocco.

Minerals are inorganic micronutrients which play variety of roles in numerous metabolic pathways in the human. Therefore, deficiency of these minerals is linked to certain medical conditions including diabetes, cardiovascular disorders, aging, and kidney problems. ${ }^{5}$ Magnesium (Mg) is one of the important minerals, ranking at fourth in its abundance in the world after calcium $(\mathrm{Ca})$, sodium $(\mathrm{Na})$ and potassium (K). ${ }^{6}$ The importance of $\mathrm{Mg}$ can be recognized by the fact that it works as a cofactor for more than 300 enzymes involved in fundamental reactions occurring in numerous essential anabolic and catabolic processes like ATP generation, glycemic control, signal transduction, DNA replication and repair, and blood pressure maintenance. ${ }^{7,8}$

Magnesium has been reported to be low in metabolic disorders, especially in the patients with T2DM. ${ }^{9}$ In this context, the deficiency of $\mathrm{Mg}$ is associated with insulin resistance, poor glycemic control, carbohydrate intolerance, lipid disorder and diabetic complications. ${ }^{10}$ Therefore, poor intracellular $\mathrm{Mg}$ concentration results in insulin resistance and higher $\mathrm{Mg}$ levelsenhance insulin sensitivity. ${ }^{11}$ The exact role of $\mathrm{Mg}$ in the pathogenesis of insulin resistance and T2DM is yet to be elucidated. However, studies have demonstrated that hypomagnesemia leads to defective tyrosine kinase activity, impaired insulin receptor activity, and exacerbated insulin resistance in the patients with T2DM..$^{11,12}$ On the other hand, adequate $\mathrm{Mg}$ level enhances tyrosine kinase phosphorylation, resulting in increased insulin sensitivity and improved glycemic control. ${ }^{11}$

Hypomagnesemia has been reported to be $44 \%$ in non-critically ill patients with T2DM which, in turn, is associated with poor glycemic control and complications like diabetic retinopathy, neuropathy, coronary artery disease and ischemic stroke. ${ }^{10}$ However, the role of $\mathrm{Mg}$ in diabetes is still controversial. Some studies have favored the beneficial effects of $\mathrm{Mg}$ supplements in diabetes in terms of glycemic control and insulin sensitivity while others have negated any significant effect of $\mathrm{Mg}$ in diabetes. ${ }^{11}$ Therefore, further research is required to elucidate the detailed role of $\mathrm{Mg}$ in the patients with diabetes. Therefore, this study was designed to evaluate magnesium status in the diabetic patients in Morocco.

\section{Materials and methods}

A descriptive study including 103 patients with T2DM was carried out at Avicenne Military Hospital in Marrakech over a period of four 
months (October 2019-January 2020). Inclusion criteria included all the patients with T2DM and age above 35years, attending the outpatient clinic of diabetes. Exclusion criteria included the diabetic patients who were on vitamin supplements containing magnesium, and those who were suffering from cancer or autoimmune diseases. An informed consent was obtained on a consent form every patient willing to be included in the study. An operating sheet was used to collect demographic data, personal history of patients, clinical characteristics and laboratory - related data. Blood samples were obtained from the patients, and were processed in the biochemistry laboratory of the military hospital. Blood samples were analyzed for fasting blood sugar, lipid profile, $\mathrm{HbA1c}$, and serum magnesium. The $\mathrm{Mg}$ status was assessed by measuring the magnesemia by colorimetric method on $\operatorname{Cobas}{ }^{\circledR}$ 6000. The reference value taken for $\mathrm{Mg}$ was $0.65-1.05 \mathrm{mmol} / \mathrm{L}$.

Categorical variables were described by the relative percentages in the relevant subject groups, differences in proportions were compared with the Chi-square test or Fisher's exact test. Continuous variables were described by the mean and standard deviation (SD). Pearson correlation was used to analyse the association betweenmagnesium and fasting and HbAlc. All analyses were carried out using the statistical program SPSS (SPSS Statistics 16.0; SPSS Inc, Chicago, IL, USA). Statistical significance was considered at $P<0.05$.

\section{Results}

A total of 103 patients were included in the study where 56 (54.4\%) were males and $47(45.6 \%)$ females. Mean age of the patients and duration of diabetes were $59 \pm 9$ years and $9 \pm 4$ years, respectively (Table 1). Oral anti-diabetic therapy (OAD), insulin therapy, and insulin plus OAD were recorded in $54.4 \%, 29.1 \%$, and $16.5 \%$ patients, respectively. Most common antecedent conditions were dyslipidemia (43.7\%), hypertension (42.7\%), and retinopathy (25.2\%) (Table 1).

Table I Demographic and clinical characteristics of the patients

\begin{tabular}{|c|c|c|c|}
\hline \multicolumn{2}{|c|}{ Characteristics } & \multirow{2}{*}{$\begin{array}{l}\text { Frequency (n) } \\
47\end{array}$} & \multirow{2}{*}{$\begin{array}{l}\text { Percent (\%) } \\
45.6\end{array}$} \\
\hline & Female & & \\
\hline Genat & Male & 56 & 54.4 \\
\hline \multicolumn{2}{|c|}{ Age in year (mean $\pm S D)$} & \multicolumn{2}{|l|}{$59 \pm 09.0$} \\
\hline \multicolumn{2}{|c|}{$\begin{array}{l}\text { Duration of diabetes in year } \\
(\text { mean } \pm S D)\end{array}$} & \multicolumn{2}{|l|}{$09 \pm 04.0$} \\
\hline \multirow{3}{*}{ Therapy } & Oral anti-diabetics & 56 & 54.4 \\
\hline & Insulin & 30 & 29.1 \\
\hline & Insulin+ OAD & 17 & 16.5 \\
\hline \multirow{6}{*}{ Antecedents } & Dyslipidaemia & 45 & 43.7 \\
\hline & $\begin{array}{l}\text { Arterial } \\
\text { hypertension }\end{array}$ & 44 & 42.7 \\
\hline & Retinopathy & 26 & 25.2 \\
\hline & Nephropathy & 12 & 11.7 \\
\hline & $\begin{array}{l}\text { Coronaryartery } \\
\text { disease }\end{array}$ & 10 & 9.7 \\
\hline & Neuropathy & 8 & 7.8 \\
\hline
\end{tabular}

Mean values for fasting blood sugar, $\mathrm{HbAlc}$ and serum magnesium were $\quad 9.38 \pm 3.73 \mathrm{mmol} / \mathrm{L}, \quad 8.11 \pm 2.01 \%$, and $0.8 \pm 0.12 \mathrm{mmol} / \mathrm{L}$, respectively. Similarly, mean values for total cholesterol, HDL cholesterol, LDL cholesterol, and triglycerides were $4.34 \pm 1.02 \mathrm{mmol} / \mathrm{L}, 1.20 \pm 0.25 \mathrm{mmol} / \mathrm{L}, 2.41 \pm 0.84 \mathrm{mmol} / \mathrm{L}$, and $1.49 \pm 0.62 \mathrm{mmol} / \mathrm{L}$, respectively (Table 2 ).
Table 2 Biological parameters of the patients

\begin{tabular}{lll}
\hline Parameter & Mean & Standard deviation \\
\hline Fasting blood sugar $(\mathrm{mmol} / \mathrm{l})$ & 9.38 & 3.73 \\
HbAIC $(\%)$ & $8.1 \mathrm{I}$ & $2.0 \mathrm{I}$ \\
Total cholesterol $(\mathrm{mmol} / \mathrm{l})$ & 4.34 & 1.02 \\
HDL Cholesterol $(\mathrm{mmol} / \mathrm{l})$ & $\mathrm{I} .2$ & 0.25 \\
LDL Cholesterol $(\mathrm{mmol} / \mathrm{l})$ & $2.4 \mathrm{I}$ & 0.84 \\
Triglycerides $(\mathrm{mmol} / \mathrm{l})$ & $\mathrm{I} .49$ & 0.62 \\
Serum magnesium $(\mathrm{mmol} / \mathrm{l})$ & 0.8 & 0.12
\end{tabular}

Hypomagnesemia was recorded in $14.56 \%$ cases. Hypomagnesemia was significantly associated with $\mathrm{HbAlc}(\mathrm{P}=0.003)$ and arterial hypertension $(\mathrm{P}=0.002$; Table 3).However, age, gender, duration of diabetes, retinopathy, nephropathy, neuropathy, coronary artery disease, dyslipidemia, and alcohol did not show significant association with hypomagnesemia $(\mathrm{P}>0.05$; Table 3$)$.

Table 3 Characteristics of patients associated with hypomagnesemia

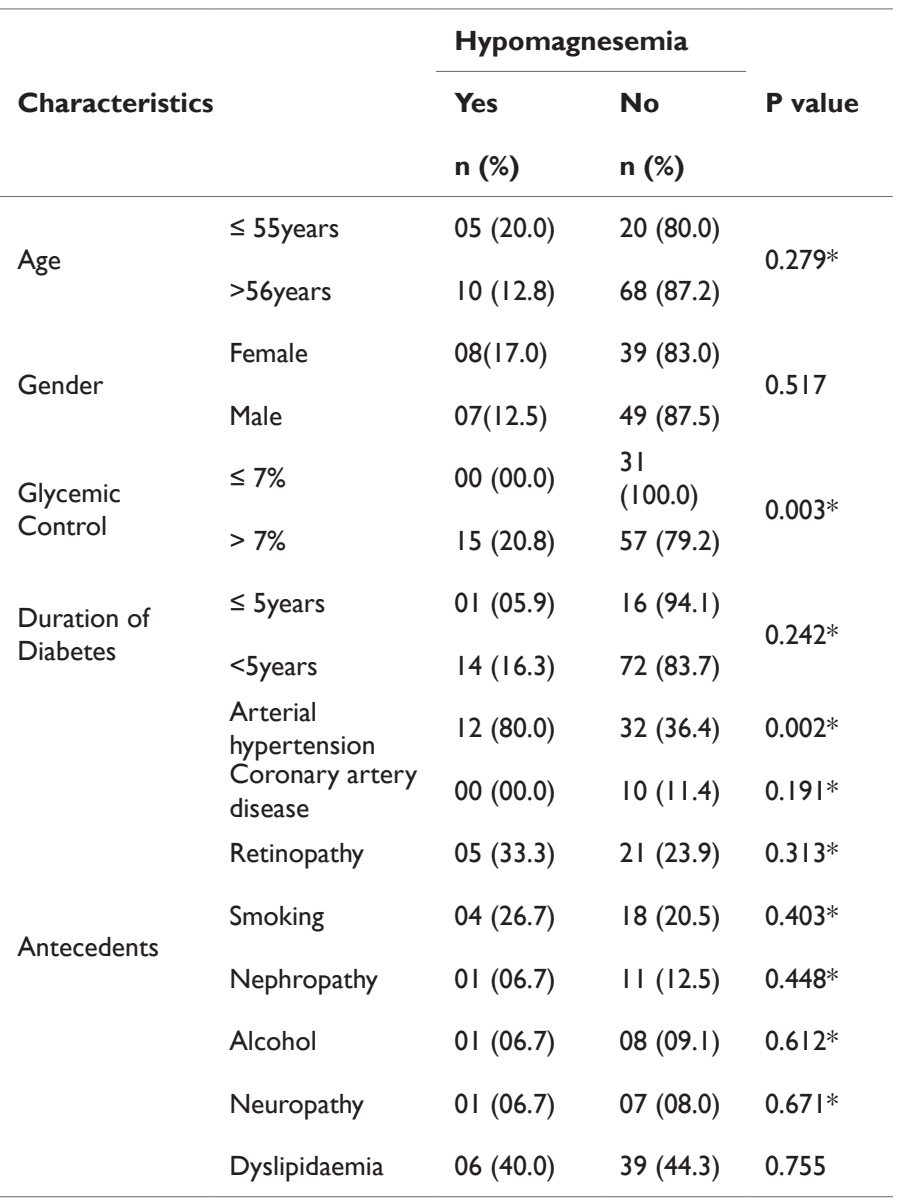

Pearson correlation showed that magnesium had negative linear relationship with fasting blood sugar higher $(r=-0,37, p<0,001)$ and HbA1c $(r=-0,41, p<0,001)$ (Figure 1) (Figure 2). It means higher the fasting blood sugar or $\mathrm{HbA1c}$, the deeper the hypomagnesemia. 


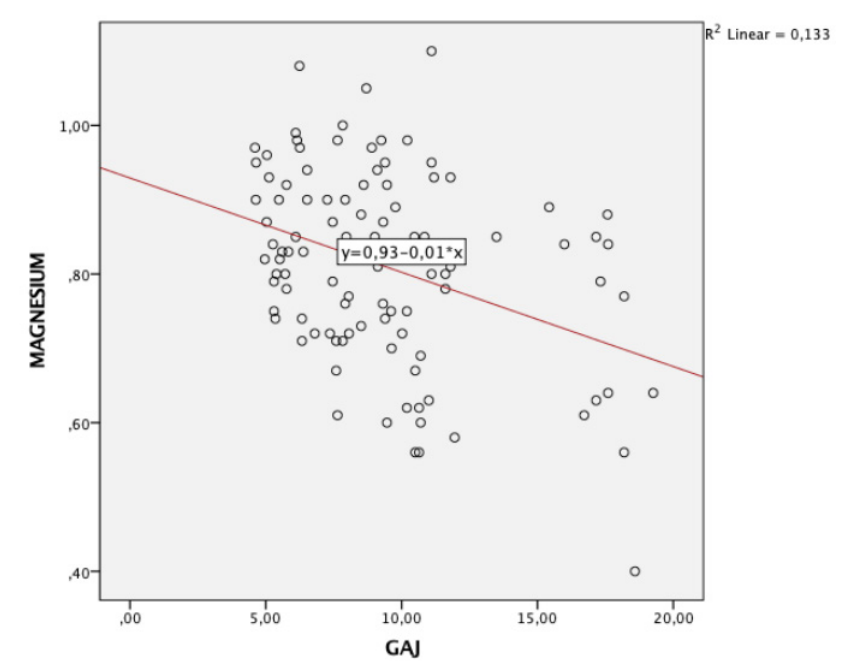

Figure I Association between magnesium level and fasting blood sugar.

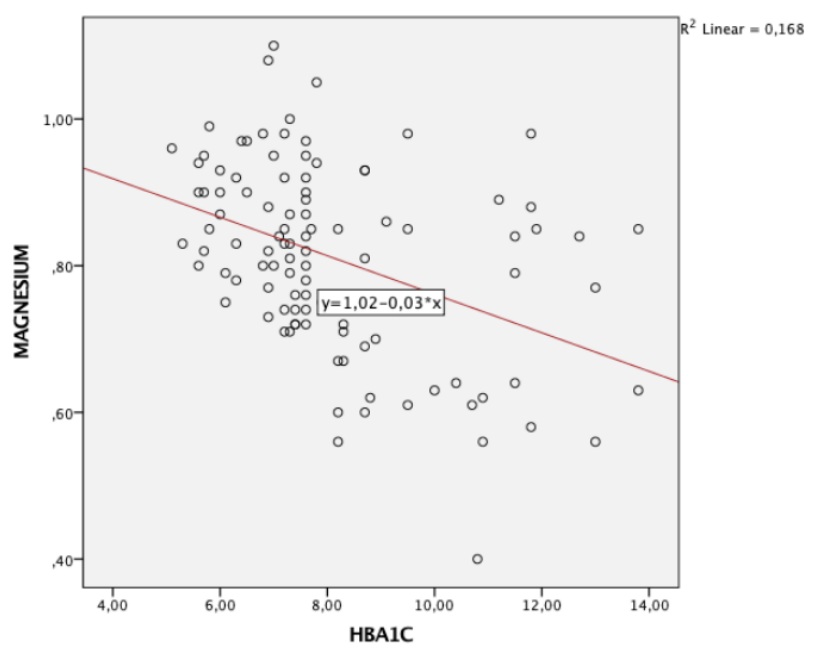

Figure 2 Association between magnesium level and $\mathrm{HbAlc}$.

\section{Discussion}

This cross sectional study was carried out to determine magnesium status in the patients with T2DM living in Morocco. The study revealed the prevalence of hypomagnesemia in $14.56 \%$ patients with T2DM presenting at Avicenne Military Hospital in Marrakech.The present study revealed significant association of hypomagnesemia with $\mathrm{HbA} 1 \mathrm{c}$ and arterial hypertension. Although the prevalence of hypomagnesemia in T2DM patient was lower than the other regions of the world; however,negative linear relationship of hypomagnesemia with fasting blood sugar supports the positive role of $\mathrm{Mg}$ in the glycemic control in the patients with T2DM.

Hypomagnesemia has frequently been reported in the patients with T2DM and this prevalence of hypomagnesemia rises with the duration of diabetes. ${ }^{13}$ The prevalence of hypomagnesemia ranges from 14 to $48 \%$ in the patients with T2DM as compared to 2.5 to $15 \%$ in healthy non-diabetic individuals. ${ }^{14}$ Comparatively, the present study revealed only $14.56 \%$ prevalence of hypomagnesemia in the patients with $\mathrm{T} 2 \mathrm{DM}$ which is lower than that reported in the other regions of the world. In Abbottabad Pakistan, Noor et al. reported hypomagnesemia in $33.89 \%$ patients with T2DM. ${ }^{13}$ Similarly, in Karachi Pakistan, Hasan et al. ${ }^{15}$ reported hypomagnesemia in 30\% patients with T2DM.

In North India, Kumar et al. ${ }^{10}$ carried out a cross sectional study including 250 patients with T2DM in order to determine the association or serum $\mathrm{Mg}$ with T2DM and diabetic retinopathy. They reported hypomagnesemia in $44 \%$ cases with poorly controlled fasting blood sugar, post-prandial blood sugar and HbAlc. They also demonstrated that hypomagnesemia is associated with poor glycemic control and increased risk of diabetic retinopathy.The varied prevalence of hypomagnesemia in T2DM patients may be attributed to various factors including poor dietary intake, impaired insulin metabolism, stressors, glomerular hyperfiltration and acid and electrolytes imbalance. ${ }^{16}$

The present study revealed negative linear relationship between magnesium level and $\mathrm{HbA1c}$. This finding has already been reported in previous studies. Arpaci et al. ${ }^{17}$ studied 673 diabetic patients in order to determine association among serum magnesium level, glycemic regulation and diabetic complications. They reported poor glycemic control in diabetic patients with depleted $\mathrm{Mg}$ level and weak negative correlation between $\mathrm{Mg}$ level and HbAlc. Similarly, Kumar et al. ${ }^{10}$ reported significant association between hypomagnesemia and $\mathrm{HbA} 1 \mathrm{c}$ level. Odusan et al. ${ }^{18}$ studied the pattern of $\mathrm{Mg}$ in 125 T2DM patients in Nigeria. They reported HbA1c significantly high in the patients with hypomagnesemia. Similar to findings of the present study, Babikr et al. ${ }^{19}$ studied 220 patients with T2DM and reported high significant negative relationship of $\mathrm{Mg}$ level with fasting blood sugar, $\mathrm{HbAlc}$ and metabolic index.

On the contrary, Saeed et al. ${ }^{19}$ evaluated magnesium level and its correlation with HbA1c in Duhok Iraq, including 100 T2DM patients. They reported normal magnesium level in $95 \%$ patients and revealed no significant correlation of magnesium with $\mathrm{HbAlc}$. Although numerous studies have reported negative linear relationship between magnesium level and $\mathrm{HbAlc}$; however, further studies at large scale with large sample size are required to reach the final relationship between these two variables.

The present study also revealed significant association between hypomagnesemia and arterial blood pressure. It has been postulated that low $\mathrm{Mg}$ level in T2DM results in the activation of $\mathrm{Na}^{+}-$ $\mathrm{Cl}^{-}$cotransporter and sodium re-absorption from kidneys, leading to elevated blood pressure. ${ }^{14}$ Odusan et al. ${ }^{18}$ also reported association between hypomagnesemia and hypertension.

The limitations of the present study include small sample size and involvement of only single center as the outcome variable may be affected by the large sample size from different multiple centers. ${ }^{20}$

\section{Conclusion}

In conclusion, the prevalence of hypomagnesemia is although low in Morocco; however, significant association of $\mathrm{Mg}$ level with fasting blood sugar and $\mathrm{HbA} 1 \mathrm{c}$ indicates positive role of $\mathrm{Mg}$ in the glycemic control in T2DM.

This study is a useful addition to the literature on $\mathrm{Mg}$ and T2DM in Morocco, paving way for further research and subsequent development of improved management strategies for T2DM.

\section{Acknowledgments}

None. 


\section{Funding}

None.

\section{Conflicts of interest}

The authors declare that they have no competing interests.

\section{References}

1. Zheng Y, Ley SH, Hu FB. Global aetiology and epidemiology of type 2 diabetes mellitus and its complications. Nat Rev Endocrinol. 2018;14(2):88-98.

2. Galicia-Garcia U, Benito-Vicente A, Larrea-Sebal A, et al. Pathophysiology of type 2 diabetes mellitus. Int $J$ Mol Sci. 2020;21(17):6275

3. Khan MAB, Hashim MJ, King JK, et al. Epidemiology of type 2 diabetes - global burden of disease and forecasted trends. J Epidemiol Glob Health. 2020;10(1):107-111.

4. World Health Organization. 2016.

5. Heffernan SM, Horner K, De Vito G, et al. The role of mineral and trace element supplementation in exercise and athletic performance: a systematic review. Nutrients. 2019;11(3):696.

6. Schwalfenberg GK, Genius SJ. The importance of magnesium in clinical healthcare. Scientifica (Cairo). 2017;2017:4179326.

7. Al Alawi AM, Majoni SW, Falhammar H. Magnesium and human health: perspectives and research directions. Int $J$ Endocrinol. 2018;2018:9041694.

8. RalecC, Henry E, Lemor M, et al. Calcium-driven DNA synthesis by a high-fidelity DNA polymerase. Nucleic Acids Res. 2017;45(21):1242512440 .

9. Zhang Y, Li Q, Xin Y, et al. Association between serum magnesium and common complications of diabetes mellitus. Technol Health Care. 2018;26(Suppl 1):379-387.
10. Kumar P, Bhargava S, Agarwal PK, et al. Association of serum magnesium with type 2 diabetes mellitus and diabetic retinopathy. $J$ Family Med Prim Care. 2019;8(5):1671-1677.

11. El Derawi WA, Naser IA, Taleb MH, et al. The effects of oral magnesium supplementation on glycemic response among type 2 diabetes patients. Nutrients. 2019;11(1):44.

12. Dasgupta A, Sarma D, Saikia UK. Hypomagnesemia in type 2 diabetes mellitus. Indian J Endocrinol Metab. 2012;16(6):1000-1003.

13. Noor MM, Nazir Q, Khan TM, et al. Association between low serum magnesium level and type 2 diabetes mellitus in Abbottabad. J Ayub Med Coll Abbottabad. 2019;31(2):226-229.

14. Gommers LMM, Hoenderop JGJ, Bindels RJM, et al. Hypomagnesemia in type 2 diabetes: a vicious circle? Diabetes. 2016;65(1):3-13.

15. Hasan M, Sultan S, Ashfaq S, et al. Hypomagnesemia in type ii diabetes mellitus patients; an experience from a tertiary care center. Ann Pak Inst Med Sci. 2017;13(2):146-150.

16. Pham PCT, Pham PMT, Pham SV, et al. Hypomagnesemia in patients with type 2 diabetes. Clin J Am Soc Nephrol. 2007;2(2):366-373.

17. Arpaci D, Tocoglu AG, Ergenc H, Korkmaz S, Ucar A, Tamer A. Associations of serum Magnesium levels with diabetes mellitus and diabetic complications. Hippokratia. 2015;19(2):153-157.

18. Odusan OO, Familoni OB, Odewabi AO, et al. Patterns and correlates of serum magnesium levels in subsets of type 2 diabetes mellitus patients in Nigeria. Indian J Endocrinol Metab. 2017;21(3):439-442.

19. Babikr WG, Shalayel MHF, Abdelraheem AHMK, et al. Impact of body mass index on hypomagnesemia and hypocalcemia in type 2 diabetic patients. Biomed Pharmacol J. 2016;9(3):933-940.

20. Saeed H, Haj S, Qasim B. Estimation of magnesium level in type 2 diabetes mellitus and its correlation with HbAlc level. Endocrinol Diabetes Metab. 2019;2(1):e0048. 